\title{
Toll-like receptors and prostate cancer
}

\author{
Shu Zhao ${ }^{1,2 t}$, Yifan Zhang ${ }^{1+}$, Qingyuan Zhang ${ }^{2}$, Fen Wang ${ }^{1}$ and Dekai Zhang ${ }^{\text {* }}$ \\ 1 Institute of Biosciences and Technology, Texas A\&M University Health Science Center, Houston, TX, USA \\ 2 Department of Medical Oncology, Affiliated Tumor Hospital of Harbin Medical University, Harbin, China
}

\section{Edited by:}

Anton G. Kutikhin, Russian Academy of Medical Sciences, Russia

\section{Reviewed by:}

F. Ronchese, Malaghan Institute of Medical Research, New Zealand

Alessio Paone, Sapienza University of Rome, Italy

Arseniy E. Yuzhalin, University of

Oxford, UK

*Correspondence:

Dekai Zhang, IBT-CIID, Texas A\&M University Health Science Center,

2121 West Holcombe Blvd., Houston,

TX 77030, USA

e-mail:dzhang@ibt.tamhsc.edu

${ }^{+}$Shu Zhao and Yifan Zhang have contributed equally to this work.
Prostate cancer is the second leading cause of cancer-related death in men after lung cancer. Immune responses clearly play a critical role in the tumorigenesis and in the efficacy of radiation therapy and chemotherapy in prostate cancer; however, the underlying molecular mechanisms are still poorly understood. Toll-like receptors (TLRs) are a well-known family of pattern recognition receptors that play a key role in host immune system. Recent studies demonstrate that there are links between TLRs and cancer; however, the function and biological importance of TLRs in prostate cancer seems complex. To elucidate the role of TLRs and innate immunity in prostate cancer might provide us with a better understanding of the molecular mechanisms of this disease. Moreover, utilizing the agonists or antagonists of TLRs might represent a promising new strategy against prostate cancer. In this review, we summarize recent advances on the studies of association between TLR signaling and prostate cancer, TLR polymorphisms and prostate cancer risk, and provide some insights about TLRs as potential targets for prostate cancer immunotherapy.

Keywords: toll-like receptor, TLR signaling, prostate cancer, innate immunity, immunotherapy

\section{INTRODUCTION}

Based on the latest cancer statistics, prostate cancer predictably ranks first among all the cancers in men and second in cancerrelated deaths in the United States in 2014 (1). Treatments against prostate cancer, including chemotherapy and radiotherapy, could improve survival; however, many patients will endure relapse and metastasis, which eventually leads to death. These treatments also destroy cancer cells and normal cells alike. Therefore, a more effective and less toxic therapy needs discovery. A promising strategy for dramatically preventing cancer development and improving cancer treatment might rely on immunotherapy. Immune evasion is a hallmark of cancer pathogenesis. Cancer cells escape from immune attack through a variety of mechanisms. A compromised immune system and chronic inflammation increase the incidence of cancer development. Inflammation has been proposed as the seventh hallmark of cancer (2) and an excellent review has elegantly summarized the role of inflammation in prostate cancer development and potential underlying mechanisms (3). Immunotherapy, which utilizes host immune system to fight cancer, has been recently highlighted with several advantages including specificity, less side effects, and less likely to develop resistance. It could be achieved in two ways: stimulating immune system to attack cancer cells or taking away the inhibitory machinery to the immune system in cancer. One potential approach to modulate immune system is targeting pattern recognition receptors (PRRs) in innate immune system, among which toll-like receptors are most well studied.

\section{TOLL-LIKE RECEPTOR: A WELL-KNOWN FAMILY OF PATTERN RECOGNITION RECEPTORS IN INNATE IMMUNITY}

Toll-like receptors are a family of transmembrane receptors that play a key role in the innate immunity. TLRs prevent invading pathogens by recognizing pathogen-associated molecular patterns (PAMPs), which are highly conserved components derived from bacteria, viruses, fungi, and parasites $(4,5)$. It can also recognize endogenous damage-associated molecular patterns (DAMPs) in different disorders and diseases such as cancer $(4,5)$. At present, 10 TLRs have been identified in human. TLR1s, TLR2, TLR4, TLR5, and TLR6 are expressed on cell surface; however, TLR3, TLR7, TLR8, and TLR9 are found exclusively within endosomes (Figure 1). Different TLRs exhibit specificity for ligand recognition. TLR2 recognizes bacterial lipoproteins, TLR3 recognizes double-stranded RNA/polyinosinic-polycytidylic acid [poly (I:C)], TLR4 recognizes lipopolysaccharides (LPS), TLR5 recognizes flagellin, TLR7 recognizes single-stranded RNA, and TLR9 recognizes CpG-containing DNA (CpG-ODN) (6-11). TLR10 is so far an orphan receptor and highly expressed in the human spleen (12) and B cells (13). Upon activation, TLRs transmit signals through one or more of four adaptor proteins: myeloid differentiation factor 88 (MyD88), TICAM1 (also known as TRIF), TIRAP (also known as MAL), and TICAM2 (also known as TRAM and TIRP). All TLRs (except for TLR3) and IL-1 receptor family members signal through MyD88. TLR3 signals through TRIF pathway; TLR4 signals through both the MyD88 and the TRIF pathways (4). Stimulation of TLRs leads to activation of NF- $\mathrm{B}$, MAPKs, Jun N-terminal kinases (JNKs), p38, and ERKs, as well as interferon regulatory factor (IRF3, IRF5, and IRF7) signaling pathways, which results in the production of inflammatory cytokines (14). Activation of TLRs in antigen-presenting cells (APC) also triggers adaptive immunity. TLRs have also been shown to regulate cell death and increase expression of the anti-apoptotic proteins Bcl2-related protein A1 (BCL2A1), inhibitor of apoptosis 1 (cIAP1), cIAP2, XIAP, and Bcl-2 family members (15).

\section{TLR EXPRESSION AND FUNCTION IN PROSTATE CANCER}

Toll-like receptors are predominantly expressed in innate immune cells such as dendritic cells, macrophages, and natural killing 


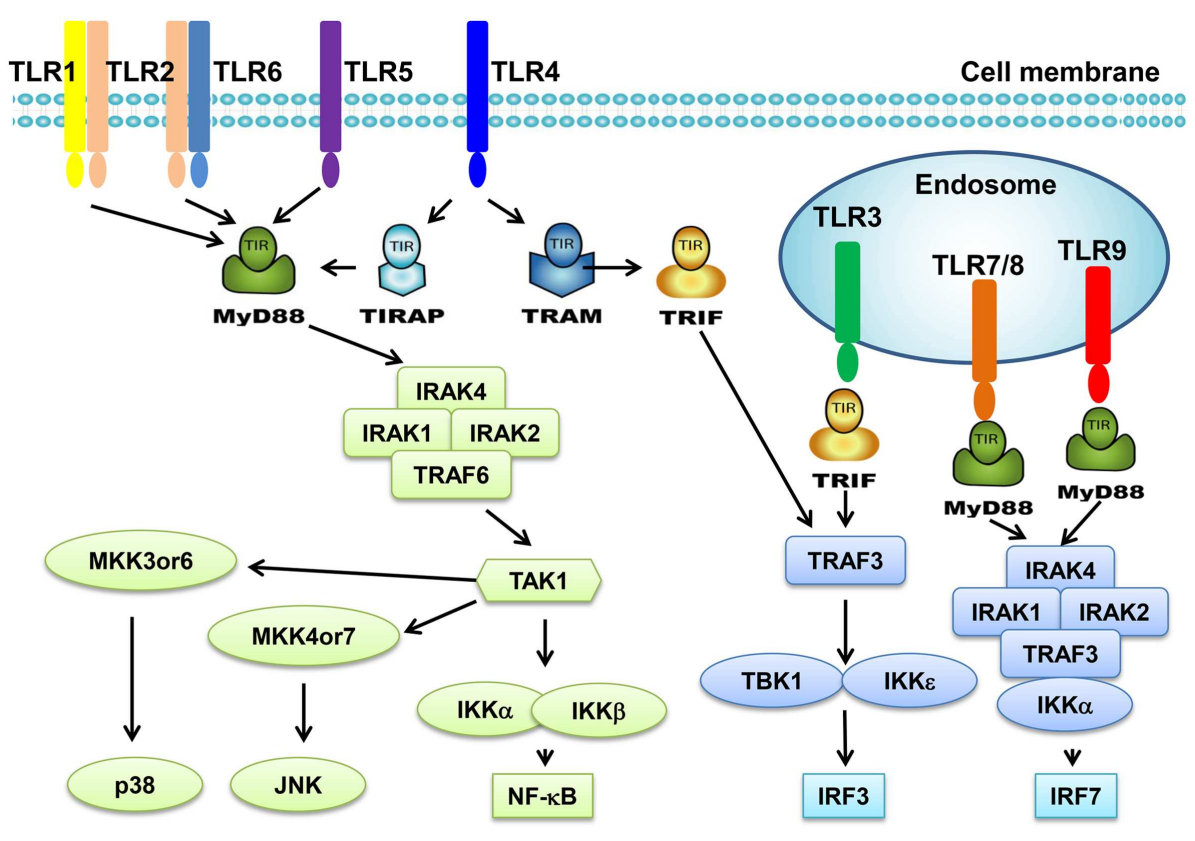

Pro-inflammatory cytokines

Type 1 IFN

FIGURE 1 | Toll-like receptors and TLR-mediated signaling pathway. TLR1 and TLR6 recognize their ligands as heterodimers with TLR2. For TLR4, MD2, and CD14 are required for LPS recognition and signaling. TLR3, TLR4, TLR5, TLR7, and TLR9 are currently thought to deliver their signal by forming homodimers after interacting with their ligands. TLR3, TLR7/8, and TLR9 are intracellular TLRs and are involved in the recognition of nucleic acids. Most TLRs, except for TLR3, signal through MyD88 pathway to activate NF-KB and AP1. TLR3 and TLR4 can signal through MyD88-independent pathway (TRIF pathway) to activate INF- $\beta$.
(NK) cells. Activation of TLRs in these cells leads to the activation of innate immunity and results in the production of pro-inflammatory cytokines, chemokines, as well as adhesion molecules, and then facilitates the activation of adaptive immunity (16). Intriguingly, growing evidence has demonstrated that TLRs are also expressed in tumor cells. TLR activation in tumor cells and its activation in tumor microenvironment such as in typical innate immune cells lead to a complex scenario (Figure 2); therefore, the activation of TLRs might play a "double-edged sword" role in the influence of tumor progression.

In most cases, it is difficult to figure out a specific pathogen to activate TLR signaling in prostate cancer. An endogenous TLR ligand, DAMPs released from damaged and/or necrotic tissues, might play a pivotal role. In term of endogenous TLR ligands in cancer, HMGB1 can activate TLR2 and TLR4 (17), and versican acts as a TLR2 agonist (18). Peroxiredoxin 1 (Prx1) appears to be an agonist of TLR4 in prostate cancer development (19). Perhaps, there are more endogenous TLR ligands that need to be further identified and verified.

The activation of some TLRs might prevent the tumor growth of prostate cancer (Figure 2). It has been shown that TLR3 is expressed in prostate cancer cells (20-25). TLR3 mRNA is detected in three prostate cancer cells lines including LNCaP, PC3, and DU-145. TLR3 mRNA level was clearly enhanced in prostate cancer cells by stimulating with poly (I:C), which suggests a functional role of TLR3 in prostate cancer (20). TLR3 protein was also expressed at similar levels in LNCaP and DU145 cells, with a slightly lower expression in PC3 cells. Treatment with poly (I:C) rapidly triggered NF- $\mathrm{KB}$-dependent expression of inflammatory molecules. Condition medium from poly (I:C)-treated LNCap and DU145 cells recruited leukocyte subpopulation, indicating that TLR3 activation might influence early immune responses in tumor microenvironment (25). Stimulation with poly (I:C) strongly suppressed prostate tumor growth in vivo, perhaps due to increased infiltration of $\mathrm{T}$ lymphocytes and NK cells in a type I IFN-dependent manner (24). In human prostate cancer patients, 85 in 112 prostate carcinomas samples showed positive expression of TLR3. High TLR3 expression level was significantly associated with high probability of the recurrence of prostate cancer (23). Paone and colleagues found that TLR3 could regulate the process of angiogenesis and apoptosis in prostate cancer cells through hypoxia-inducible factor $1 \alpha$ (HIF$1 \alpha)$ and PKC-dependent mechanism $(21,22)$. TLR5 is expressed in LNCap and DU-145 by which stimulation triggers the production of chemokines that recruit immune cells, including NK cells and cytotoxic CD8 cells, which most likely contribute to tumor inhibition (25).

The activation of other TLRs might play a different role in the tumor growth of prostate cancer (Figure 2). The expression of TLR4 in prostate cancer has been demonstrated in several animal models. Studies revealed a constitutive expression of TLR4 in the epithelial cells of rat ventral prostate as well as in a rat 


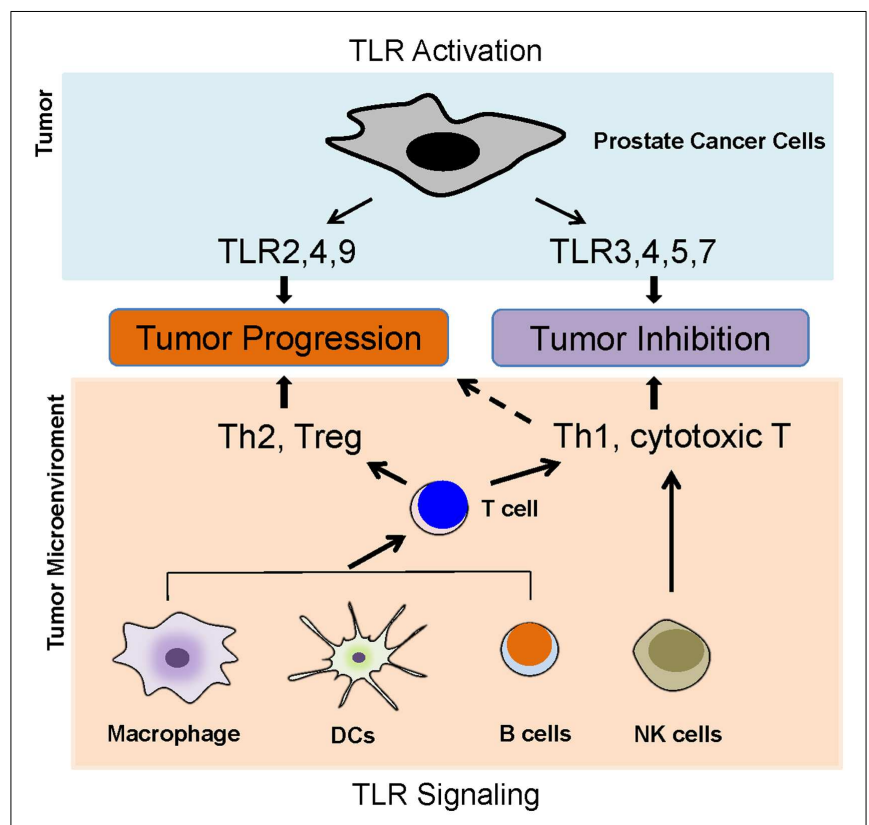

FIGURE 2 |Toll-like receptors and prostate cancer. TLR activation in tumor cells and its activation in tumor microenvironment such as in typical innate immune cells lead to a complex scenario, which determines the role of TLRs in prostate cancer development. The activation of TLRs in antigen-presenting cells, such as DCs, macrophages, and B cells, can lead to either Th1 and T cytotoxic responses or Th2 and Treg responses. The activations of TLR2, 4, and 9 in prostate cancer cells appear to promoter tumor growth, but the activation of TLR3, 4, 5, and 7 might inhibit prostate cancer.

adenocarcinoma cell line and in prostate primary culture cells $(26,27)$. TLR4 is also expressed in DU-145, PC3, and normal prostate gland in both stroma and epithelium $(28,29)$. In addition, TLR4 has also been shown to be expressed in clinical samples of prostate cancer. Initially, TLR9 expression was thought to be restricted to immune cells, but recent studies have showed that a variety of tumor cell types including prostate cancer also express functional TLR9 $(23,30,31)$. A clinical study demonstrated that TLR9 is expressed in prostate cancer specimens (23). Joanna et al. found that TLR9 is expressed in human prostate cancer cell lines LnCaP, C4-2B, Du-145, PC3, and in clinical samples of prostate cancer through immunohistochemistry and western blotting, but not in MDA Pca2b and stromal cells of the clinical adenocarcinoma samples (32). TLR9 expression was also statistically significantly increased in prostate cancer epithelium and stroma, compared with the same cellular compartments in benign hyperplasia, especially in the most poorly differentiated forms (30).

The function and biological importance of TLRs in prostate cancer seems complex (Figure 2). Perhaps the distinct and unidentified TLR signaling pathways are activated in cancer cells or innate immune cells during tumor progression; or, the first activation of TLR in cancer cells or innate immune cells markedly affect the subsequently activation and induced effectors. The mystery will be further investigated and will affect the potential of TLR agonists or antagonists as anti-tumor therapeutic agents.

\section{MicroRNA REGULATE TLRs IN PROSTATE CANCER}

MicroRNAs (miRNAs) are a class of small non-coding RNAs ( $22 \mathrm{nt}$ in length), which negatively regulate gene expression at the post-transcriptional level (33). By binding to target sequences within the $3^{\prime}$ UTR of mRNA, miRNAs induce gene silencing by either inhibiting translation or leading to degradation of mRNA. MiRNA alterations are shown to be involved in both initiation and progression of human cancer (34-39). Deregulation of miRNAs is implicated as an important mechanism in tumorigenesis and several miRNAs have been proposed as oncogenes or tumor suppressors (40-42).

MicroRNAs are emerging as a fundamental mechanism in the regulation of TLR signaling (43-47). Recent works have linked miRNAs and TLRs in prostate cancer. MiR-29a has been shown as a potential tumor suppressor miRNA to regulate TRAF-4 expression in metastatic prostate cancer (48). TLR3 activation by poly (I:C) induces upregulation of miRNAs including miR-29b, -29c, $-148 \mathrm{~b}$, and -152 , which target DNA methyltransferases and leads to reexpression of oncosuppressor RAR $\beta$ in prostate cancer cells (49). TLRs activation facilitates either prostate cancer inhibition or progression. MiRNAs are likely to act as important regulators to control TLRs expression and signaling, thus contribute to prostate cancer development.

\section{TLR SIGNALING IN PROSTATE CANCER}

Toll-like receptor signaling pathway has been well defined in innate immune cells. TLR ligation recruits one or more adaptor proteins such as MyD88, TRIF, Mal, and TRAM though TIR domain interactions. Most TLRs except TLR3 go through a MyD88-dependent signaling pathway. MyD88 engagement activates IL-1 receptor associated kinase (IRAK), which interacts with tumor necrosis factor receptor associated factor 6 (TRAF6), resulting in the activation of MAPK and NF- $\kappa \mathrm{B}$ signaling. TLR3 and TLR4 activate a MyD88-independent signaling pathway. TRIF is recruited upon stimulation and leads to the activation of NF- $\kappa$ B and type I IFN signaling.

Although TLR3 can be activated in prostate cancer cells, the molecular signaling pathway has not been fully elucidated. A recent study in human prostate cancer cells suggests that TLR3 signaling triggers apoptosis and growth arrest of LNCaP cells partially through inactivation of the PI3K/Akt pathway. CyclinD1, c-Myc, $\mathrm{p} 53$, and NOXA are indicated to play a role in poly (I:C)-treated LNCaP cells (20). In other studies, HIF- $1 \alpha$ facilitates apoptosis through a PKC-dependent mechanism in poly (I:C)-treated prostate cancer cells. TLR3 activation by poly (I:C) activates JNK and p38 through PKC- $\alpha$ and triggers apoptosis in a caspase- 8 dependent manner $(21,22)$. In LNCap cells, poly (I:C) treatment upregulates a pattern of chemokines, including CCL3, CCL4, CCL5, CCL8, CXCL9, and CXCL10, which could induce massive NK cell and CD8 T cell chemotaxis. Moreover, poly (I:C) induced the expression of inflammatory molecules such as IL-6 and IL-12, which are NF- $\mathrm{B}$ signaling dependent (25). In TRAMP tumor model, poly (I:C) treatment recruits NK cells and T lymphocytes through a type I IFN dependent mechanism, resulting in suppression of tumor growth (24). TLR5 agonist flagellin can activate NF- $\kappa \mathrm{B}$ signaling in LNCaP and DU145 cells, and lead to the production of pro-inflammatory molecules (25). 
Stimulation of TLR4 in DU145 by LPS activates NF- $\kappa$ B signaling pathway, which leads to production of pro-inflammatory cytokines such as IL- 6 and IL- $1 \beta$ through MyD88-dependent pathway (29). In addition, TLR4 activation increases expression of VEGF and TGF- $\beta 1$ in PC3 cells, which promote tumor development (28). Also, knockdown of TLR4 using siRNA in PC3 cells reduces tumor cell migration and invasion (50). TLR9 stimulation by CpG-ODN plays an important role in prostate cancer invasion. This effect is mediated by activating NF- $\kappa \mathrm{B}$ and upregulation of COX-2 (31). TLR9 expression in prostate cancer cells has similarly been found to enhance invasiveness via induction of MMP-13 in vitro (32). In both studies, CpG-ODN stimulation did not affect cellular proliferation, which suggests TLR9 signaling plays a role in cancer progression and metastasis.

These defined TLR signaling pathways seem difficult to help understand why the activation of some TLRs such as TLR3 inhibits tumor growth but the activation of other TLRs such as TLR2 promotes tumor growth (Figure 2). Some distinct TLR signal pathways must exist to determine the specific effectors in the different TLR activations leading opposite consequences.

\section{TLR GENE POLYMORPHISMS AND PROSTATE CANCER RISK}

Polymorphisms in TLR genes are reportedly related to susceptibility of a large spectrum of infectious and inflammatory diseases. Growing evidence suggest that chronic intra-prostatic inflammation contribute to prostate cancer progression. It was suggested that TLR gene polymorphisms might alter TLR signaling, thus affecting inflammation and prostate cancer risk. A number of studies have been done to investigate whether there is a connection between TLR gene polymorphisms and prostate cancer risk, and the results are controversial $(51,52)$.

Single nucleotide polymorphisms (SNPs) in TLR4 were reported to be associated with prostate cancer risk in several studies (53-58). Sequence variants in TLR gene cluster (TLR6-TLR1TLR10) were also reported to be associated with prostate cancer risk $(51,52)$. However, controversial results were also obtained. Shui and colleagues investigated 10 SNPs in TLR4 and found no significant correlation between TLR4 genetic variation and prostate cancer risks (59). Chen et al. reported that sequence variants of gene cluster TLR6-TLR1-TLR10 were not associated with the risk of prostate cancer (60). A meta-analysis by Lindström et al. did not show clear correlation between TLR gene polymorphisms and prostate cancer risks.

The discrepancies among these results might be due to multiple factors including detection method, the race of population, and sample size. It is important to clarify this issue because it will determine not only whether the TLR polymorphisms can be used as a diagnosis/prognosis marker but also whether we can develop a novel strategy to treat prostate cancer by targeting TLRs and their signaling pathway. A more comprehensive study including a sufficient sample size should be performed to investigate the association between TLR gene polymorphisms and prostate cancer risk.

TARGETING TLRS FOR PROSTATE CANCER IMMUNOTHERAPY The ability of TLRs to manipulate prostate cancer development has raised the interests in developing immunotherapy against prostate cancer with the TLR agonists or antagonists. Actually, three drugs targeting TLRs have been approved by FDA for use in cancer patients: the bacillus Calmette-Guérin (BCG), monophosphoryl lipid A (MPL), and imiquimod (61). BCG is prepared from an attenuated strain of Mycobacterium bovis and activates TLR2/4. BCG is used as a vaccine in prevention of tuberculosis, but also for treatment of in situ bladder carcinoma. Derived from LPS as a potent TLR4 agonist, MPL is an active component of Cervarix, which is used against cancer-causing human papillomavirus (HPV) $(62,63)$. Imiquimod, one of the most successful drugs targeting TLRs, is a synthetic imidazoquinoline that signals though TLR7 and is commonly used in the treatment of skin cancer such as basal cell carcinoma and Bowen's disease (64-66). Imiquimod induces the proinflammatory cytokines including IFN $\alpha$, IL-6, and TNF- $\alpha$ (67). The activation of TLR7/8 leads to a Th1 response and an anti-tumor activity, which depends on IFN $\gamma$ (68). In prostate cancer, to support this concept, Han et al., reported that Imiquimod can inhibit both human and mouse prostate cancer growth by inducing apoptosis $(69,70)$.

A number of preclinical and clinical studies are ongoing to investigate the immunotherapeutic potency utilizing TLRs against prostate cancer. TLR3 activation directly triggers apoptosis of human prostate cancer cells (21); therefore, TLR3 agonists have potential to be developed as anti-tumor therapeutic agents. Indeed, Ampligen, composed of poly (I:C) (a TLR3 agonist), has been shown to inhibit a variety of tumor growth in early clinical trials $(71,72)$. Hiltonol, a particular formulation of poly (I:C), is currently in Phase I/II clinical trial to evaluate its safety and efficacy (71). Meanwhile, a phase 2 clinical study (NCT00514072) utilizing a BCG vaccine to treat prostate cancer is ongoing. A multi-peptide, dual-adjuvant telomerase vaccine (GX301) in which Imiquimod is an active component showed less toxic and highly immunogenic in prostate cancer patients, but requires future studies to determine its clinical efficacy (73). Furthermore, TLR4 stimulation by LPS is shown to contribute to chemoresistance to docetaxel in prostate cancer cells (74).

\section{CONCLUDING REMARKS}

Toll-like receptors play a critical role in innate immunity. TLRs are expressed not only in innate immune cells, but also in nonimmune cells including cancer cells. Functional expression of TLRs has been linked to prostate cancer development. TLRs may serve as a double-edged sword in prostate cancer tumorigenesis by promoting malignant transformation of epithelial cells and tumor growth, or on the contrary, inducing apoptosis, and inhibiting tumor progression. The consequences might be dependent on complex signaling networks triggered by TLRs activation and tumor microenvironment. Genetic variations and polymorphisms of TLRs have been associated with prostate cancer; however, the results are inconclusive and need further validation $(75,76)$. The ability of boosting immune responses but with less serious side effect makes TLRs a good target to treat cancers. A wave of preclinical and clinical studies showed the potential of developing treatment targeting TLRs against prostate cancer. Based on these researches, one of the most probable approaches is to use agents targeting TLRs as adjuvants along with other treatments $(67,68$, $71,77,78)$. Above all, elucidation of the mechanisms of cancer cell 
TLR signaling and crosstalk with other signaling pathways as well as the mechanisms of cancer progression will definitely provide a promising novel strategy for cancer treatment.

\section{ACKNOWLEDGMENTS}

We thank Navella Richard and Mar'Kiffany Lane for critical reading of the manuscript. This work is supported partially by $\mathrm{NIH}$ grant R21CA176698 and TAMHSC development grant (to Dekai Zhang).

\section{REFERENCES}

1. Siegel R, Ma J, Zou Z, Jemal A. Cancer statistics, 2014. CA Cancer J Clin (2014) 64(1):9-29. doi:10.3322/caac.21208

2. Hanahan D, Weinberg RA. Hallmarks of cancer: the next generation. Cell (2011) 144(5):646-74. doi:10.1016/j.cell.2011.02.013

3. De Marzo AM, Platz EA, Sutcliffe S, Xu J, Gronberg H, Drake CG, et al. Inflammation in prostate carcinogenesis. Nat Rev Cancer (2007) 7(4):256-69. doi: $10.1038 / \mathrm{nrc} 2090$

4. Takeda K, Kaisho T, Akira S. Toll-like receptors. Annu Rev Immunol (2003) 21:335-76. doi:10.1146/annurev.immunol.21.120601.141126

5. Janeway CA Jr. Approaching the asymptote? Evolution and revolution in immunology. Cold Spring Harb Symp Quant Biol (1989) 54(Pt 1):1-13. doi: 10.1101/SQB.1989.054.01.003

6. Poltorak A, He X, Smirnova I, Liu MY, Van Huffel C, Du X, et al. Defective LPS signaling in $\mathrm{C} 3 \mathrm{H} / \mathrm{HeJ}$ and $\mathrm{C} 57 \mathrm{BL} / 10 \mathrm{ScCr}$ mice: mutations in Tlr4 gene. Science (1998) 282(5396):2085-8. doi:10.1126/science.282.5396.2085

7. Aliprantis AO, Yang RB, Mark MR, Suggett S, Devaux B, Radolf JD, et al. Cell activation and apoptosis by bacterial lipoproteins through toll-like receptor-2. Science (1999) 285(5428):736-9. doi:10.1126/science.285.5428.736

8. Hemmi H, Takeuchi O, Kawai T, Kaisho T, Sato S, Sanjo H, et al. A toll-like receptor recognizes bacterial DNA. Nature (2000) 408(6813):740-5. doi:10.1038/ 35047123

9. Alexopoulou L, Holt AC, Medzhitov R, Flavell RA. Recognition of doublestranded RNA and activation of NF-kappaB by toll-like receptor 3. Nature (2001) 413(6857):732-8. doi:10.1038/35099560

10. Hayashi F, Smith KD, Ozinsky A, Hawn TR, Yi EC, Goodlett DR, et al. The innate immune response to bacterial flagellin is mediated by toll-like receptor 5. Nature (2001) 410(6832):1099-103. doi:10.1038/35074106

11. Heil F, Hemmi H, Hochrein H, Ampenberger F, Kirschning C, Akira S, et al. Species-specific recognition of single-stranded RNA via toll-like receptor 7 and 8. Science (2004) 303(5663):1526-9. doi:10.1126/science.1093620

12. Hasan U, Chaffois C, Gaillard C, Saulnier V, Merck E, Tancredi S, et al. Human TLR10 is a functional receptor, expressed by B cells and plasmacytoid dendritic cells, which activates gene transcription through MyD88. J Immunol (2005) 174(5):2942-50. doi:10.4049/jimmunol.174.5.2942

13. Hornung V, Rothenfusser S, Britsch S, Krug A, Jahrsdorfer B, Giese T, et al. Quantitative expression of toll-like receptor 1-10 mRNA in cellular subsets of human peripheral blood mononuclear cells and sensitivity to CpG oligodeoxynucleotides. J Immunol (2002) 168(9):4531-7. doi:10.4049/jimmunol.168.9.4531

14. Lee MS, Kim YJ. Signaling pathways downstream of pattern-recognition receptors and their cross talk. Annu Rev Biochem (2007) 76:447-80. doi:10.1146/ annurev.biochem.76.060605.122847

15. Salaun B, Romero P, Lebecque S. Toll-like receptors' two-edged sword: when immunity meets apoptosis. Eur J Immunol (2007) 37(12):3311-8. doi:10.1002/ eji.200737744

16. Iwasaki A, Medzhitov R. Toll-like receptor control of the adaptive immune responses. Nat Immunol (2004) 5(10):987-95. doi:10.1038/ni1112

17. Apetoh L, Ghiringhelli F, Tesniere A, Obeid M, Ortiz C, Criollo A, et al. Tolllike receptor 4-dependent contribution of the immune system to anticancer chemotherapy and radiotherapy. Nat Med (2007) 13(9):1050-9. doi:10.1038/ nm1622

18. Kim S, Takahashi H, Lin WW, Descargues P, Grivennikov S, Kim Y, et al. Carcinoma-produced factors activate myeloid cells through TLR2 to stimulate metastasis. Nature (2009) 457(7225):102-6. doi:10.1038/nature07623

19. Riddell JR, Bshara W, Moser MT, Spernyak JA, Foster BA, Gollnick SO. Peroxiredoxin 1 controls prostate cancer growth through toll-like receptor 4dependent regulation of tumor vasculature. Cancer Res (2011) 71(5):1637-46. doi:10.1158/0008-5472.CAN-10-3674
20. Harashima N, Inao T, Imamura R, Okano S, Suda T, Harada M. Roles of the PI3K/Akt pathway and autophagy in TLR3 signaling-induced apoptosis and growth arrest of human prostate cancer cells. Cancer Immunol Immunother (2012) 61(5):667-76. doi:10.1007/s00262-011-1132-1

21. Paone A, Starace D, Galli R, Padula F, De Cesaris P, Filippini A, et al. Tolllike receptor 3 triggers apoptosis of human prostate cancer cells through a PKC-alpha-dependent mechanism. Carcinogenesis (2008) 29(7):1334-42. doi:10.1093/carcin/bgn149

22. Paone A, Galli R, Gabellini C, Lukashev D, Starace D, Gorlach A, et al. Toll-like receptor 3 regulates angiogenesis and apoptosis in prostate cancer cell lines through hypoxia-inducible factor 1 alpha. Neoplasia (2010) 12(7): 539-49. doi:10.1593/neo.92106

23. Gonzalez-Reyes S, Fernandez JM, Gonzalez LO, Aguirre A, Suarez A, Gonzalez JM, et al. Study of TLR3, TLR4, and TLR9 in prostate carcinomas and their association with biochemical recurrence. Cancer Immunol Immunother (2011) 60(2):217-26. doi:10.1007/s00262-010-0931-0

24. Chin AI, Miyahira AK, Covarrubias A, Teague J, Guo B, Dempsey PW, et al. Toll-like receptor 3-mediated suppression of TRAMP prostate cancer shows the critical role of type I interferons in tumor immune surveillance. Cancer Res (2010) 70(7):2595-603. doi:10.1158/0008-5472.CAN-09-1162

25. Galli R, Starace D, Busa R, Angelini DF, Paone A, De Cesaris P, et al. TLR stimulation of prostate tumor cells induces chemokine-mediated recruitment of specific immune cell types. J Immunol (2010) 184(12):6658-69. doi:10.4049/ jimmunol.0902401

26. Quintar AA, Roth FD, De Paul AL, Aoki A, Maldonado CA. Toll-like receptor 4 in rat prostate: modulation by testosterone and acute bacterial infection in epithelial and stromal cells. Biol Reprod (2006) 75(5):664-72. doi:10.1095/biolreprod. 106.053967

27. Gatti G, Rivero V, Motrich RD, Maccioni M. Prostate epithelial cells can act as early sensors of infection by up-regulating TLR4 expression and proinflammatory mediators upon LPS stimulation. J Leukoc Biol (2006) 79(5):989-98. doi:10.1189/jlb.1005597

28. Pei Z, Lin D, Song X, Li H, Yao H. TLR4 signaling promotes the expression of VEGF and TGFbetal in human prostate epithelial PC3 cells induced by lipopolysaccharide. Cell Immunol (2008) 254(1):20-7. doi:10.1016/j.cellimm. 2008.06.007

29. Gatti G, Quintar AA, Andreani V, Nicola JP, Maldonado CA, Masini-Repiso $\mathrm{AM}$, et al. Expression of toll-like receptor 4 in the prostate gland and its association with the severity of prostate cancer. Prostate (2009) 69(13):1387-97. doi:10.1002/pros.20984

30. Vaisanen MR, Vaisanen T, Jukkola-Vuorinen A, Vuopala KS, Desmond R, Selander KS, et al. Expression of toll-like receptor-9 is increased in poorly differentiated prostate tumors. Prostate (2010) 70(8):817-24. doi:10.1002/pros.21115

31. Di JM, Pang J, Sun QP, Zhang Y, Fang YQ, Liu XP, et al. Toll-like receptor 9 agonists up-regulates the expression of cyclooxygenase-2 via activation of NF-kappaB in prostate cancer cells. Mol Biol Rep (2010) 37(4):1849-55. doi:10.1007/s11033-009-9620-5

32. Ilvesaro JM, Merrell MA, Swain TM, Davidson J, Zayzafoon M, Harris KW, et al. Toll like receptor-9 agonists stimulate prostate cancer invasion in vitro. Prostate (2007) 67(7):774-81. doi:10.1002/pros.20562

33. He L, Hannon GJ. MicroRNAs: small RNAs with a big role in gene regulation. Nat Rev Genet (2004) 5(7):522-31. doi:10.1038/nrg1415

34. Lu J, Getz G, Miska EA, Alvarez-Saavedra E, Lamb J, Peck D, et al. MicroRNA expression profiles classify human cancers. Nature (2005) 435(7043):834-8. doi:10.1038/nature03702

35. Calin GA, Croce CM. MicroRNA signatures in human cancers. Nat Rev Cancer (2006) 6(11):857-66. doi:10.1038/nrc1997

36. Calin GA, Croce CM. MicroRNA-cancer connection: the beginning of a new tale. Cancer Res (2006) 66(15):7390-4. doi:10.1158/0008-5472.CAN-06-0800

37. Esquela-Kerscher A, Slack FJ. Oncomirs - microRNAs with a role in cancer. Nat Rev Cancer (2006) 6(4):259-69. doi:10.1038/nrc1840

38. Croce CM. Causes and consequences of microRNA dysregulation in cancer. Nat Rev Genet (2009) 10(10):704-14. doi:10.1038/nrg2634

39. Garzon R, Calin GA, Croce CM. MicroRNAs in cancer. Annu Rev Med (2009) 60:167-79. doi:10.1146/annurev.med.59.053006.104707

40. Zhang B, Pan X, Cobb GP, Anderson TA. MicroRNAs as oncogenes and tumor suppressors. Dev Biol (2007) 302(1):1-12. doi:10.1016/j.ydbio.2006.08.028

41. Shenouda SK, Alahari SK. MicroRNA function in cancer: oncogene or a tumor suppressor? Cancer Metastasis Rev (2009) 28(3-4):369-78. doi:10.1007/s10555009-9188-5 
42. Ventura A, Jacks T. MicroRNAs and cancer: short RNAs go a long way. Cell (2009) 136(4):586-91. doi:10.1016/j.cell.2009.02.005

43. Nahid MA, Satoh M, Chan EK. MicroRNA in TLR signaling and endotoxin tolerance. Cell Mol Immunol (2011) 8(5):388-403. doi:10.1038/cmi.2011.26

44. O'Neill LA, Sheedy FJ, McCoy CE. MicroRNAs: the fine-tuners of tolllike receptor signalling. Nat Rev Immunol (2011) 11(3):163-75. doi:10.1038/ nri2957

45. Quinn SR, O’Neill LA. A trio of microRNAs that control toll-like receptor signalling. Int Immunol (2011) 23(7):421-5. doi:10.1093/intimm/dxr034

46. Fabbri M, Paone A, Calore F, Galli R, Gaudio E, Santhanam R, et al. MicroRNAs bind to toll-like receptors to induce prometastatic inflammatory response. Proc Natl Acad Sci U S A (2012) 109(31):E2110-6. doi:10.1073/pnas.1209414109

47. He X, Jing Z, Cheng G. MicroRNAs: new regulators of toll-like receptor signalling pathways. Biomed Res Int (2014) 2014:945169. doi:10.1155/2014/945169

48. Ahmed F, Shiraishi T, Vessella RL, Kulkarni P. Tumor necrosis factor receptor associated factor-4: an adapter protein overexpressed in metastatic prostate cancer is regulated by microRNA-29a. Oncol Rep (2013) 30(6):2963-8. doi:10.3892/ or.2013.2789

49. Galli R, Paone A, Fabbri M, Zanesi N, Calore F, Cascione L, et al. Toll-like receptor 3 (TLR3) activation induces microRNA-dependent reexpression of functional RARbeta and tumor regression. Proc Natl Acad Sci U S A (2013) 110(24):9812-7. doi:10.1073/pnas.1304610110

50. Hua D, Liu MY, Cheng ZD, Qin XJ, Zhang HM, Chen Y, et al. Small interfering RNA-directed targeting of toll-like receptor 4 inhibits human prostate cancer cell invasion, survival, and tumorigenicity. Mol Immunol (2009) 46(15):2876-84. doi:10.1016/j.molimm.2009.06.016

51. Sun J, Wiklund F, Zheng SL, Chang B, Balter K, Li L, et al. Sequence variants in toll-like receptor gene cluster (TLR6-TLR1-TLR10) and prostate cancer risk. J Natl Cancer Inst (2005) 97(7):525-32. doi:10.1093/jnci/dji070

52. Stevens VL, Hsing AW, Talbot JT, Zheng SL, Sun J, Chen J, et al. Genetic variation in the toll-like receptor gene cluster (TLR10-TLR1-TLR6) and prostate cancer risk. Int J Cancer (2008) 123(11):2644-50. doi:10.1002/ijc.23826

53. Zheng SL, Augustsson-Balter K, Chang B, Hedelin M, Li L, Adami HO, et al. Sequence variants of toll-like receptor 4 are associated with prostate cancer risk: results from the Cancer Prostate in Sweden Study. Cancer Res (2004) 64(8):2918-22. doi:10.1158/0008-5472.CAN-03-3280

54. Chen YC, Giovannucci E, Lazarus R, Kraft P, Ketkar S, Hunter DJ. Sequence variants of toll-like receptor 4 and susceptibility to prostate cancer. Cancer Res (2005) 65(24):11771-8. doi:10.1158/0008-5472.CAN-05-2078

55. Cheng I, Plummer SJ, Casey G, Witte JS. Toll-like receptor 4 genetic variation and advanced prostate cancer risk. Cancer Epidemiol Biomarkers Prev (2007) 16(2):352-5. doi:10.1158/1055-9965.EPI-06-0429

56. Song J, Kim DY, Kim CS, Kim HJ, Lee DH, Lee HM, et al. The association between toll-like receptor 4 (TLR4) polymorphisms and the risk of prostate cancer in Korean men. Cancer Genet Cytogenet (2009) 190(2):88-92. doi:10.1016/j.cancergencyto.2008.12.011

57. Wang MH, Helzlsouer KJ, Smith MW, Hoffman-Bolton JA, Clipp SL, Grinberg V, et al. Association of IL10 and other immune response- and obesityrelated genes with prostate cancer in CLUE II. Prostate (2009) 69(8):874-85. doi: $10.1002 /$ pros. 20933

58. Kim HJ, Bae JS, Chang IH, Kim KD, Lee J, Shin HD, et al. Sequence variants of Toll-like receptor 4 (TLR4) and the risk of prostate cancer in Korean men. World J Urol (2012) 30(2):225-32. doi:10.1007/s00345-011-0690-3

59. Shui IM, Stark JR, Penney KL, Schumacher FR, Epstein MM, Pitt MJ, et al. Genetic variation in the toll-like receptor 4 and prostate cancer incidence and mortality. Prostate (2012) 72(2):209-16. doi:10.1002/pros.21423

60. Chen YC, Giovannucci E, Kraft P, Lazarus R, Hunter DJ. Association between Toll-like receptor gene cluster (TLR6, TLR1, and TLR10) and prostate cancer. Cancer Epidemiol Biomarkers Prev (2007) 16(10):1982-9. doi:10.1158/10559965.EPI-07-0325

61. Vacchelli E, Galluzzi L, Eggermont A, Fridman WH, Galon J, Sautes-Fridman C, et al. Trial watch: FDA-approved toll-like receptor agonists for cancer therapy. Oncoimmunology (2012) 1(6):894-907. doi:10.4161/onci.20931

62. Mata-Haro V, Cekic C, Martin M, Chilton PM, Casella CR, Mitchell TC. The vaccine adjuvant monophosphoryl lipid A as a TRIF-biased agonist of TLR4. Science (2007) 316(5831):1628-32. doi:10.1126/science.1138963
63. Schiffman M, Wacholder S. Success of HPV vaccination is now a matter of coverage. Lancet Oncol (2012) 13(1):10-2. doi:10.1016/S1470-2045(11)70324-2

64. van Egmond S, Hoedemaker C, Sinclair R. Successful treatment of perianal Bowen's disease with imiquimod. Int J Dermatol (2007) 46(3):318-9. doi:10.1111/j.1365-4632.2007.03200.x

65. Hemmi H, Kaisho T, Takeuchi O, Sato S, Sanjo H, Hoshino K, et al. Small antiviral compounds activate immune cells via the TLR7 MyD88-dependent signaling pathway. Nat Immunol (2002) 3(2):196-200. doi:10.1038/ni758

66. Holcmann M, Drobits B, Sibilia M. How imiquimod licenses plasmacytoid dendritic cells to kill tumors. Oncoimmunology (2012) 1(9):1661-3. doi:10.4161/ onci. 22033

67. Hennessy EJ, Parker AE, O’Neill LA. Targeting toll-like receptors: emerging therapeutics? Nat Rev Drug Discov (2010) 9(4):293-307. doi:10.1038/nrd3203

68. O'Neill LA, Bryant CE, Doyle SL. Therapeutic targeting of toll-like receptors for infectious and inflammatory diseases and cancer. Pharmacol Rev (2009) 61(2):177-97. doi:10.1124/pr.109.001073

69. Han JH, Park SY, Kim JB, Cho SD, Kim B, Kim BY, et al. TLR7 expression is decreased during tumour progression in transgenic adenocarcinoma of mouse prostate mice and its activation inhibits growth of prostate cancer cells. Am J Reprod Immunol (2013) 70(4):317-26. doi:10.1111/aji.12146

70. Han JH, Lee J, Jeon SJ, Choi ES, Cho SD, Kim BY, et al. In vitro and in vivo growth inhibition of prostate cancer by the small molecule imiquimod. Int $J$ Oncol (2013) 42(6):2087-93. doi:10.3892/ijo.2013.1898

71. Galluzzi L, Vacchelli E, Eggermont A, Fridman WH, Galon J, Sautes-Fridman C, et al. Trial watch: experimental toll-like receptor agonists for cancer therapy. Oncoimmunology (2012) 1(5):699-716. doi:10.4161/onci.20696

72. Brodsky I, Strayer DR, Krueger LJ, Carter WA. Clinical studies with ampligen (mismatched double-stranded RNA). J Biol Response Mod (1985) 4(6):669-75.

73. Fenoglio D, Traverso P, Parodi A, Tomasello L, Negrini S, Kalli F, et al. A multipeptide, dual-adjuvant telomerase vaccine (GX301) is highly immunogenic in patients with prostate and renal cancer. Cancer Immunol Immunother (2013) 62(6):1041-52. doi:10.1007/s00262-013-1415-9

74. Zhang Y, Wang Y, Yuan J, Qin W, Liu F, Wang F, et al. Toll-like receptor 4 ligation confers chemoresistance to docetaxel on PC-3 human prostate cancer cells. Cell Biol Toxicol (2012) 28(4):269-77. doi:10.1007/s10565-012-9221-2

75. Kutikhin AG, Yuzhalin AE. Are toll-like receptor gene polymorphisms associated with prostate cancer? Cancer Manag Res (2012) 4:23-9. doi:10.2147/CMAR. S28683

76. Lindstrom S, Schumacher F, Siddiq A, Travis RC, Campa D, Berndt SI, et al. Characterizing associations and SNP-environment interactions for GWAS-identified prostate cancer risk markers - results from BPC3. PLoS One (2011) 6(2):e17142. doi:10.1371/journal.pone.0017142

77. Malara AE, Fedele C, Aloj L, Arra C, Laccetti P, D’Alessio G, et al. Effects of a human compact anti-ErbB2 antibody on prostate cancer. Oncol Rep (2012) 28(1):297-302. doi:10.3892/or.2012.1760

78. Gora J, Hopfgartner J, Kuess P, Paskeviciute B, Georg D. Is there room for combined modality treatments? Dosimetric comparison of boost strategies for advanced head and neck and prostate cancer. J Radiat Res (2013) 54(Suppl 1):i97-112. doi:10.1093/jrr/rrt067

Conflict of Interest Statement: The authors declare that the research was conducted in the absence of any commercial or financial relationships that could be construed as a potential conflict of interest.

Received: 28 March 2014; paper pending published: 08 April 2014; accepted: 09 July 2014; published online: 23 July 2014.

Citation: Zhao S, Zhang Y, Zhang Q, Wang F and Zhang D (2014) Toll-like receptors and prostate cancer. Front. Immunol. 5:352. doi: 10.3389/fimmu.2014.00352

This article was submitted to Tumor Immunity, a section of the journal Frontiers in Immunology.

Copyright (c) 2014 Zhao, Zhang, Zhang, Wang and Zhang. This is an open-access article distributed under the terms of the Creative Commons Attribution License (CC $B Y)$. The use, distribution or reproduction in other forums is permitted, provided the original author(s) or licensor are credited and that the original publication in this journal is cited, in accordance with accepted academic practice. No use, distribution or reproduction is permitted which does not comply with these terms. 